\title{
Comparison of intravenous infusions of iloprost and oral nifedipine in treatment of Raynaud's phenomenon in patients with systemic sclerosis: a double blind randomised study
}

\author{
M Rademaker, E D Cooke, N E Almond, J A Beacham, R E Smith, T G K Mant, J D Kirby
}

Departments of

Dermatology and Medical Electronics, St

Bartholomew's Hospital, London EC1A 7BE

M Rademaker, MRCP, registrar

E D Cooke, MD, director of thermographic unit

N E Almond, PHD, research fellow

J A Beacham, BSC, scientific officer

R E Smith, PHD, senior

physicist

J D Kirby, MRCP, consultant

physician

Drug Research Unit, Guy's Hospital, London SE1 9RT T G K Mant, MRCP, research registrar

Correspondence to: $\mathrm{Dr}$ Cooke.

BrMed f 1989;298:561-4
Abstract

Objective-To compare the long term effects of short term intravenous infusions of iloprost with those of oral nifedipine in patients with Raynaud's phenomenon associated with systemic sclerosis.

Design-Double blind, placebo controlled, randomised group comparison.

Setting-Dermatology outpatient clinic.

Patients - Twenty three patients with Raynaud's phenomenon associated with well documented systemic sclerosis (American Rheumatism Association criteria) and with typical abnormalities in fingernail folds on capillaroscopy.

Interventions - Twelve patients were randomised to receive intravenous infusions of iloprost starting at $0.5 \mathrm{ng} / \mathrm{kg} / \mathrm{min}$ and increased by $0.5 \mathrm{ng} / \mathrm{kg} / \mathrm{min}$ every 15 minutes to a maximum of $2.0 \mathrm{ng} / \mathrm{kg} / \mathrm{min}$ for eight hours on three consecutive days with a further single infusion at week 8 . Placebo capsules were given concurrently. Eleven patients were randomised to receive nifedipine, starting at $\mathbf{3 0} \mathrm{mg}$ daily and increased to $60 \mathrm{mg}$ daily after four weeks for another 12 weeks. Infusions of placebo were given in the same manner as the infusions of iloprost. One patient from each group withdrew because of social reasons and three patients receiving nifedipine withdrew because of side effects.

End point-Reduction in number, duration, and severity of attacks of Raynaud's phenomenon, reduction in number of digital lesions, increase in digital blood flow.

Measurements and main results-Measurements were taken at $0,4,8,12$, and 16 weeks. Both regimens produced a reduction in the number, duration, and severity of attacks of Raynaud's phenomenon. The mean (SE) number of digital lesions was reduced with iloprost (from $3.5(1.6)$ to $0.6(0.3)$ ) and with nifedipine (from $4.3(0.8)$ to 1.4 $(0.5))$ after 16 weeks. Hand temperature and digital and microcirculatory blood flow were increased with iloprost but not with nifedipine.

Conclusion-Both iloprost and nifedipine are beneficial in the treatment of Raynaud's phenomenon. With nifedipine, however, side effects are common. Short term infusions of iloprost provide longlasting relief of symptoms, and side effects occur only during the infusions and are dose dependent.

\section{Introduction}

Studies of short term infusions of epoprosteol (prostaglandin $I_{2}$ ) in the treatment of Raynaud's phenomenon in patients with systemic sclerosis suggested that the beneficial effects lasted for some weeks. ${ }^{2}$ Recently, in an open trial, we showed that patients' symptoms remained improved during winter with either oral nifedipine ${ }^{3}$ or short term (three consecutive days) infusions of iloprost (Schering AG), a stable analogue of epoprostenol. ${ }^{+}$The present study compares these two treatments when allocated to patients blind and at random.

\section{Method}

The trial was performed during the winter of 1986-7. It was a double blind, randomised group comparison of patients receiving intravenous infusions of iloprost and capsules of placebo that matched nifedipine with patients receiving capsules of nifedipine and intravenous infusions of placebo (physiological saline). Blindness of the investigators was ensured by controlling treatment at one centre (Guy's Hospital) and performing clinical and temperature and blood flow assessments separately at two independent departments of another centre (St Bartholomew's Hospital).

Thirty seven patients were recruited from the dermatology clinic. All had well documented systemic sclerosis (American Rheumatism Association criteria) and Raynaud's phenomenon and appearances typical of systemic sclerosis on capillaroscopy of the fingernail fold. ${ }^{6}$ Women either had adequate contraception or could not become pregnant. Exclusions were patients with primary Raynaud's disease, white finger induced by vibrations, abnormal haemostasis, hyperviscosity syndromes, or diabetes mellitus; patients who were being treated concurrently with nifedipine or who were known to be intolerant to it; and patients who did not give their consent. A total of 14 patients were excluded.

None of the remaining 23 patients smoked or were taking drugs with a known action on blood vessels or constituents of blood. Twelve of them were given iloprost by intravenous infusion on three consecutive days for eight hours starting at a rate of $0.5 \mathrm{ng} / \mathrm{kg} / \mathrm{min}$. The dose was increased every 15 minutes by the same increment $(0.5 \mathrm{ng} / \mathrm{kg} / \mathrm{min})$ to a maximum of $2.0 \mathrm{ng} / \mathrm{kg} /$ min, or less if the maximum dose was not tolerated. A single infusion lasting eight hours was given in the same manner during week 8 after hand temperature and blood flow measurements had been taken. Oral nifedipine $10 \mathrm{mg}$ was given as capsules to 11 patients thrice daily for four weeks and then, if this dose was tolerated well, continued at $20 \mathrm{mg}$ thrice daily for the remaining 12 weeks of the trial. The infusion of placebo was given in the same manner as the iloprost, and the placebo capsules looked identical to the nifedipine capsules. Baseline assessments were performed on two occasions before treatment was started. Subsequent measurements were made at $4,8,12$, and 16 weeks.

Efficacy was assessed subjectively using patient diary cards to record the number, duration, and severity of attacks of Raynaud's phenomenon during the week before the trial and then throughout its duration. Patients were also asked whether their symptoms improved, remained unchanged, or became worse during treatment. Objective assessment was made by recording the total number of digital lesions 
(ulcers, fissures, and paronychia) before and during treatment and by measurement of blood flow and temperature in a room in which temperature and humidity were controlled $\left(23-25^{\circ} \mathrm{C}, 30-40 \%\right) .^{?}$ Blood flow in the forearm and digits $(1 / \mathrm{min} / \mathrm{kg}$ of tissue) was obtained by venous occlusion and strain gauge plethysmography, and microcirculatory flow was measured in the finger pulp by laser Doppler flowmetry $^{8}$ and by photoplethysmography. Mean hand temperature was measured with an AGA 680 thermographic system with an integrator. ${ }^{9}$ Measurements were made for 15 minutes after mild cold stress to both hands (water at $20^{\circ} \mathrm{C}$ for one minute).

Blood pressure was recorded as the average of three measurements made with a Hawksley random zero sphygmomanometer at each laboratory visit. Peripheral vascular resistance was calculated by dividing the mean arterial blood pressure by the blood flow. ${ }^{10}$

The split plot analysis ( $F$ test $)$ for repeated measurements was used for the statistical analysis of absolute change from baseline with time. Comparisons were made with baseline measurements with either Student's paired $t$ test or the Wilcoxon matched pairs test for parametric or non-parametric data respectively. Differences were judged to be statistically significant if $p$ was less than $0 \cdot 05$.

\section{Results}

Of the 37 patients referred for possible inclusion in the trial, 14 were rejected mainly because they had previously taken nifedipine and had felt no benefit or their side effects had outweighed benefit. There was no difference between the patients receiving iloprost and those receiving nifedipine with regard to mean (SE) age (51 (3) years $v 53$ (3) years) or duration of disease $(17(4)$ years $v 15$ (4) years). Three patients were men and these were randomised to receive nifedipine.

Headache, nausea, and vomiting occurred in more than half the patients during the infusion of iloprost but passed off rapidly afterwards. These symptoms appeared to be dose related and were not severe enough to stop the infusion. Though all the patients received the maximum dose of $2.0 \mathrm{ng} / \mathrm{kg} / \mathrm{min}$ for a short time, the dose was reduced to $1.5 \mathrm{ng} / \mathrm{kg} / \mathrm{min}$ in 10 patients.

Five patients were unable to tolerate the maximum dose of nifedipine, and three others withdrew because of side effects - two with headache by week 8 and one with peripheral oedema after 12 weeks. One patient in each group withdrew for social reasons. The one who was randomised to receive iloprost withdrew immediately after baseline assessment, and the one receiving nifedipine withdrew after eight weeks. During the trial there was no change in haematological or biochemical variables that could be attributed to either drug.

TABLE I-Mean percentage change (95\% confidence intervals) from mean baseline in number and characteristics of attacks of Raynaud's phenomenon in patients with systemic sclerosis after infusion of iloprost and during treatment with nifedipine

\begin{tabular}{|c|c|c|c|c|}
\hline & \multicolumn{4}{|c|}{ No of weeks } \\
\hline & 4 & 8 & 12 & 16 \\
\hline \multicolumn{5}{|l|}{ No of attacks: } \\
\hline Iloprost & $\begin{array}{c}-21 \cdot 6 \\
(-49 \cdot 0 \text { to } 5 \cdot 8)\end{array}$ & $\begin{array}{c}-21 \cdot 9 \\
(-46 \cdot 8 \text { to } 3 \cdot 1)\end{array}$ & $\begin{array}{c}-42 \cdot 4 \\
(-75 \cdot 4 \text { to }-9 \cdot 5)\end{array}$ & $\begin{array}{c}-55 \cdot 4 \\
(-84 \cdot 5 \text { to } 26 \cdot 2)\end{array}$ \\
\hline Nifedipine & $\begin{array}{c}-26 \cdot 2 \\
(-41 \cdot 9 \text { to }-10 \cdot 5)\end{array}$ & $\begin{array}{c}-12 \cdot 2 \\
(-27 \cdot 2 \text { to } 2 \cdot 7)\end{array}$ & $\begin{array}{c}-23 \cdot 1 \\
(-45 \cdot 9 \text { to }-0.4)\end{array}$ & $\begin{array}{c}-41 \cdot 5 \\
(-71 \cdot 7 \text { to }-11 \cdot 2)\end{array}$ \\
\hline \multicolumn{5}{|l|}{ Duration of attacks: } \\
\hline Iloprost & $\begin{array}{c}-21 \cdot 0 \\
(-34 \cdot 0 \text { to }-7 \cdot 9)\end{array}$ & $\begin{array}{c}-16 \cdot 6 \\
(-36 \cdot 5 \text { to } 3 \cdot 2)\end{array}$ & $\begin{array}{c}-36 \cdot 9 \\
(-56 \cdot 9 \text { to }-16 \cdot 9)\end{array}$ & $\begin{array}{c}-46 \cdot 8 \\
(-70 \cdot 8 \text { to }-22 \cdot 8)\end{array}$ \\
\hline Nifedipine & $\begin{array}{c}12 \cdot 7 \\
(-69 \cdot 0 \text { to } 94 \cdot 3)\end{array}$ & $\begin{array}{c}-1 \cdot 41 \\
(-62 \cdot 1 \text { to } 59 \cdot 3)\end{array}$ & $\begin{array}{c}-25 \cdot 7 \\
(-41 \cdot 9 \text { to }-9 \cdot 5)\end{array}$ & $\begin{array}{c}-44 \cdot 7 \\
(-61 \cdot 6 \text { to }-27 \cdot 8)\end{array}$ \\
\hline \multicolumn{5}{|l|}{ Severity of attacks: } \\
\hline Iloprost & $\begin{array}{c}-10 \cdot 7 \\
(-20 \cdot 3 \text { to }-1 \cdot 1)\end{array}$ & $\begin{array}{c}-6.9 \\
(-24.5 \text { to } 11.5)\end{array}$ & $\begin{array}{c}-28 \cdot 5 \\
(-47 \cdot 3 \text { to }-9 \cdot 8)\end{array}$ & $\begin{array}{c}-34 \cdot 6 \\
(-63 \cdot 5 \text { to }-5 \cdot 8)\end{array}$ \\
\hline Nifedipine & $\begin{array}{c}-21 \cdot 8 \\
(-30 \cdot 2 \text { to }-13 \cdot 3)\end{array}$ & $\begin{array}{c}-16 \cdot 2 \\
(-28 \cdot 0 \text { to }-4 \cdot 5)\end{array}$ & $\begin{array}{c}-16 \cdot 0 \\
(-32 \cdot 5 \text { to } 0.5)\end{array}$ & $\begin{array}{c}-31 \cdot 5 \\
(-52 \cdot 6 \text { to }-10 \cdot 3)\end{array}$ \\
\hline
\end{tabular}

Table I shows that the mean number, duration, and severity of attacks of Raynaud's phenomenon was reduced by both drugs. Half of the patients in each group thought that their symptoms had improved, and one patient in each group thought that they had become worse. Table II shows that both drugs considerably reduced the mean number of skin lesions.

TABLE II-Mean (SE) number of skin lesions in patients with Raynaud's phenomenon associated with systemic sclerosis before and during treatment with intravenous iloprost or oral nifedipine

\begin{tabular}{lccccc}
\hline & \multicolumn{5}{c}{ No of weeks } \\
\cline { 2 - 6 } & 0 & 4 & 8 & 12 & 16 \\
\hline Iloprost & $3 \cdot 5(1 \cdot 6)$ & $0 \cdot 5(0 \cdot 2)$ & $0 \cdot 4(0 \cdot 2)^{\star}$ & $0 \cdot 4(0 \cdot 3)$ & $0 \cdot 6(0 \cdot 3)$ \\
Nifedipine & $4 \cdot 3(0 \cdot 8)$ & $1 \cdot 0(0 \cdot 4)$ & $1 \cdot 3(0 \cdot 4)$ & $1 \cdot 1(0 \cdot 6)$ & $1 \cdot 4(0 \cdot 5)$
\end{tabular}

Duncan multiple range test $\mathrm{p}<0.01$ for both treatments at $4,8,12$, and 16 weeks.
${ }^{\star} p=0.04$ Compared with patients receiving nifedipine.
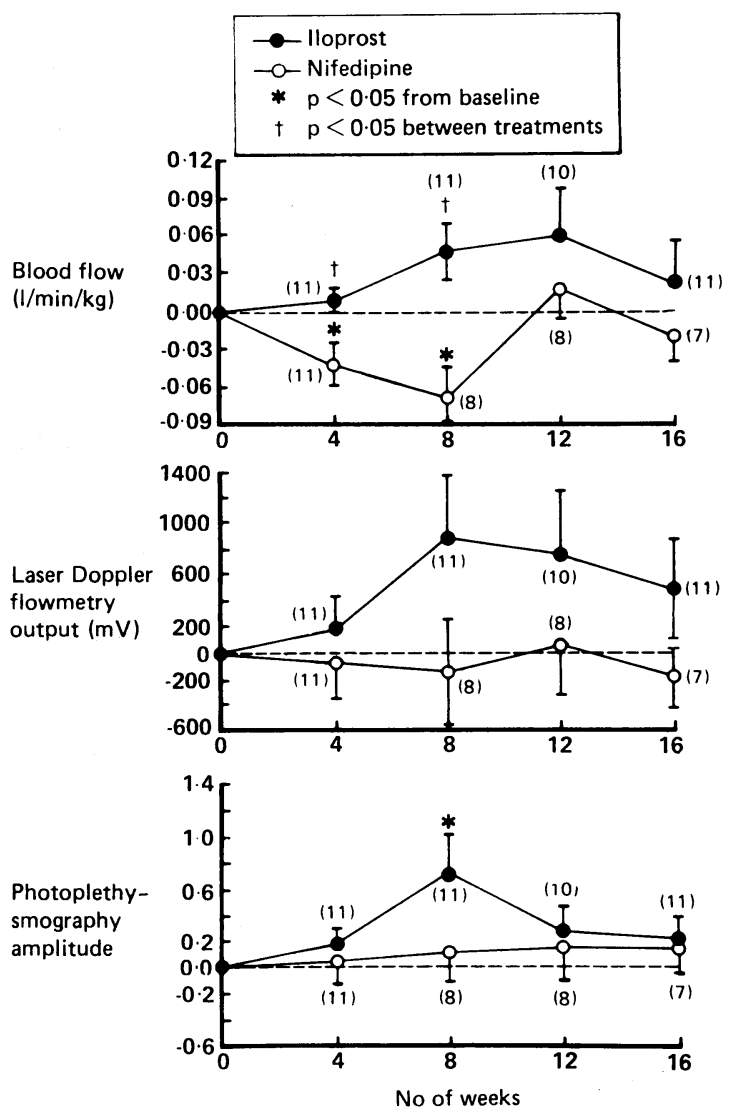

FIG 1-Mean (SE) changes from baseline in digital blood flow in patients with Raynaud's phenomenon associated with systemic sclerosis after infusion of iloprost and during treatment with nifedipine as measured by venous occlusion with strain gauge plethysmography (top); laser Doppler flowmetry (middle); and photoplethysmography pulse amplitude (bottom). Numbers in parentheses are patients analysed at each data point

Assessments of baseline blood flow were slightly higher for those receiving nifedipine than for those receiving iloprost. Consequently, mean changes from baseline were used to compare the two treatments. Figure 1 shows that digital blood flow at all time points was increased from baseline with iloprost and significantly reduced with nifedipine at weeks 4 and 8 . The overall difference between the treatments was significant. Microcirculatory flow (fig 1) at all times was increased from baseline with iloprost, and the increase was significant at week 8 . With nifedipine microcirculatory flow did not change appreciably from baseline. The increased blood flow in the digits with iloprost was accompanied by an increase in mean finger temperature. Iloprost reduced digital peripheral vas- 
cular resistance at weeks 4,8 , and 12 but not at week 16.

Figure 2 shows that mean blood pressure was reduced with both regimens, although the reduction was greater with nifedipine. This was associated with an increase in blood flow in the forearm and a significant reduction in peripheral vascular resistance in the forearm (fig 2).

\section{Discussion}

Though the values were typical of those found in systemic sclerosis, a difference in the blood flow measurements was observed between patients receiving iloprost and those receiving nifedipine, but this was possibly owing to the small number of patients. Thus in the analysis the relative change from baseline was used to compare the two treatments. One other possible source of bias was the exclusion from entry into the study of patients known to be intolerant to nifedipine. Despite the exclusion three of the 11 patients in this group dropped out during the trial by week 12 because of side effects at the lowest dose $(30$ mg daily).

In contrast, side effects with iloprost occurred only during the infusion and were those usually associated with infusion of prostanoids - that is, headache and nausea. They were not severe enough to warrant interruption of the infusion and stopped shortly after the infusion was stopped. Most of the patients, however, were able to tolerate the maximum dose (2 $\mathrm{ng} / \mathrm{kg} / \mathrm{min}$ ), though not always for the full 15 minutes. Clearly care should be taken to start the infusion with a small dose and to increase the dose incrementally and slowly, regarding minor side effects as an indication for slight reduction. Similarly, side effects with nifedipine may be avoided by starting with a low dose, $5 \mathrm{mg}$ three times daily, and increasing the dose incrementally. Both regimens were beneficial as measured by the rate of healing of digital lesions and reduction in the number, duration, and severity of painful attacks of Raynaud's phenomenon.

With the exception of our previous trial of nifedipine in patients with systemic sclerosis ${ }^{3}$ it is difficult to compare the results of this investigation with results of other studies of nifedipine in the treatment of Raynaud's phenomenon. ${ }^{11-17}$ These investigations were, with one exception, ${ }^{16}$ short (two to three weeks) and they recorded only one objective measurement of blood flow, which in some instances, as commented on by Rustin et al, ${ }^{18}$ was obtained after unreasonable stimuli." In addition most of them included patients with Raynaud's disease, in which vasospasm may be less severe and structural change in the digital vessels is slight or absent. Also when patients with systemic sclerosis were included any decreases in the numbers of digital lesions were not recorded.

The difference between the drugs may be that nifedipine is a general vasodilator with little effect on damaged digital vessels, whereas iloprost produces specific effects that increase blood flow in these vessels. This is suggested by the greater fall in mean blood pressure and the more pronounced enhancement of blood flow in the forearm and fall in peripheral vascular resistance that occur with nifedipine compared with iloprost (fig 2). The general systemic effect of nifedipine may be associated with the fall in digital blood flow and the virtually undetectable change in microcirculatory flow (fig 1), which may be due to reflex sympathetic stimulation caused by systemic vasodilatation and the fall in mean blood pressure. ${ }^{19}$ This may explain the reduction in digital blood flow and increased peripheral vascular resistance described by Lindsey $e t$ al when they used nifedipine $60 \mathrm{mg}$ daily in patients with sclerosis..$^{20}$ Considering the necessity for an intact endothelium in the relaxation of arterial smooth muscle ${ }^{212}$ it may be that the digital vessels in systemic sclerosis, in which endothelial cells are characteristically abnormal, may be most susceptible to vasoconstriction.

Digital lesions, however, healed with both regimens, suggesting that the beneficial effect of nifedipine may be brought about by a mechanism other than enhancement of blood flow-for example, alteration of mechanisms in local tissue, so protecting against the response to cold. ${ }^{23}$ Also it has been shown that nifedipine enhances thrombolysis, ${ }^{24}$ an effect which may be important in disease where this activity is known to be depressed. ${ }^{25} 26$

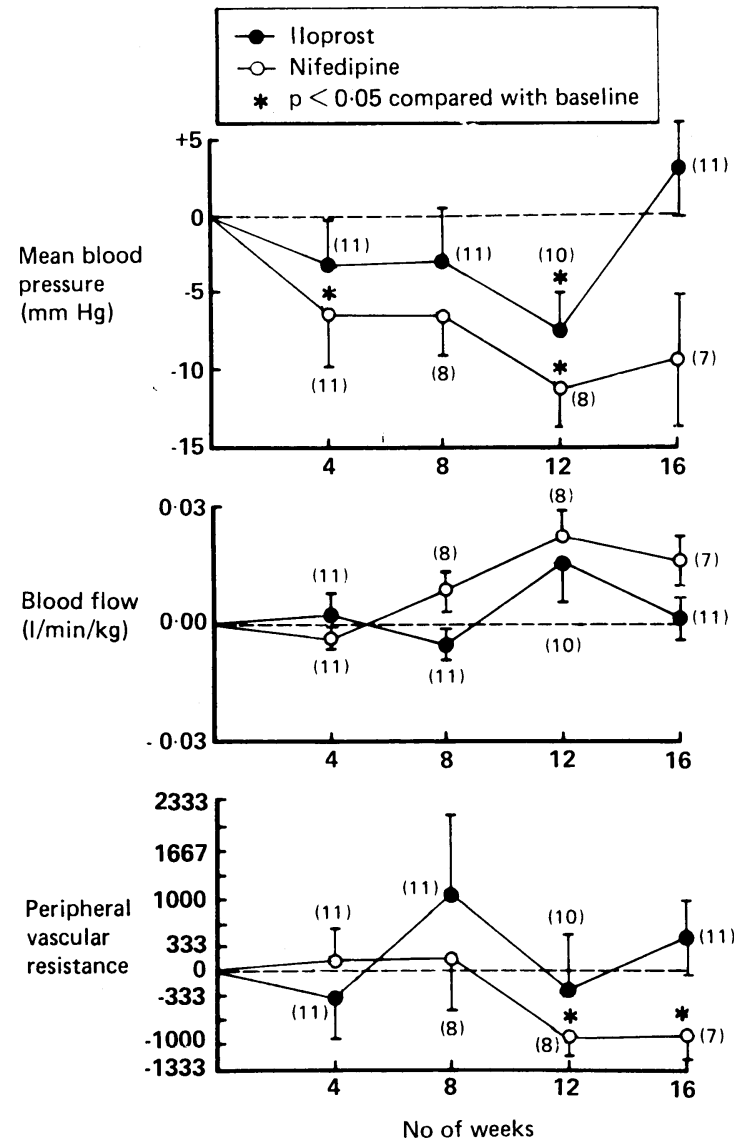

FIG 2-Mean (SE) changes from baseline in blood pressure (top); blood flow in forearm (middle); and peripheral vascular resistance in forearm (bottom) in patients with Raynaud's phenomenon associated with systemic sclerosis after infusion of iloprost and during treatment with nifedipine

Healing of the endothelial lesion accompanied by the local release of vasodilatory substances-for example, epoprostenol and nitric oxide (endothelium derived relaxing factor)-may be responsible for the enhanced digital flow that persists for weeks after infusion of iloprost. Interestingly, the effect of three consecutive daily infusions of iloprost was to increase microcirculatory blood flow (fig 1) at week 4, which became maximal at week 8 . This suggests a process of continuous repair, an effect that was maintained for a further four weeks by a single infusion but was no longer evident at week 16 . This effect must be distinct from the immediate short lived vasodilatation that occurs during infusion of a prostaglandin.

The optimum regimen for iloprost remains unclear, but a single infusion every four to six weeks or a three day course of longer infusions may provide sustained relief from peripheral ischaemia in patients with systemic sclerosis.

We thank H R Watson (Schering Health Care) for technical help and Professor G S Panayi for helpful discussion. 
1 Dowd PM, Martin MFR, Cooke ED, et al. Treatment of Raynaud's phenomenon by intravenous infusion of prostacyclin $\left(\mathrm{PGI}_{2}\right) . \mathrm{Br} f$ Dermatol 1982;106:81-9.

2 Belch JJF, Drury JK, Cappell H, et al. Intermittent epoprostenol (prostacyclin) infusion in patients with Raynaud's syndrome. Lancet 1983:ز:313-4.

Meyrick Thomas RH, Rademaker M, Grimes SM, et al Nifedipine in the treatment of Raynaud's phenomenon patients with systemic sclerosis. $\mathrm{Br} \mathcal{Z}$ Dermatol 1987;117:237-41.

4 Rademaker M, Thomas RHM, Provost G, Beacham JA, Cooke ED, Kirb JDT. Prolonged increase in digital blood flow following iloprost infusion in Jatients with systemic sclerosis. Postgrad Med f 1987;63:617-20.

5 Sub-committee for Scleroderma Criteria of the American Rheumatism

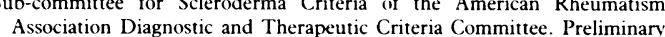
criteria for the classification of systemic sclerosis (scleroderma). Arthrit Rheum 1980:23:581-90.

6 Maricq HR. Widefield capillary microscopy. Technique and rating scale for abnormalities seen in scleroderma and related disorders. Arthritis Rheum 1981;24:1159-65

Cooke ED, Bowcock SA, Smith AT. Photoplethysmography of the distal pulp in the assessment of the vasospastic hand. Angiology 1985;36:33-9.

Almond NE, Jones DP, Cooke ED. Good quality photoplethysmograph signals derived from a laser Doppler flowmeter preliminary studies of the two outputs obtained simultaneously from the finger. $f$ Biomed Eng 1988;10:458-62.

9 Cooke ED, Bowcock SA, Smith AT. A mathematical model for the vascular behaviour of the hands in response to cold stress. Vascular Medicine 1985;3:98-104.

10 Bennett T, Hosking DJ, Hampton JR. Cardiovascular responses to lower bod negative pressure in normal subjects and in patients with diabetes mellitus.

11 Smith CD, McKendry R. Controlled trial of nifedipine in the treatment of Raynaud's phenomenon. Lancet 1982;ii:1299-301.

12 Winston EL, Pariser KM, Miller KB, et al. Nifedipine as a therapeutic modality for Raynaud's phenomenon. Arthritis Rheum 1983;26:1177-80.

13 Rodeheffer RJ, Rommer JA, Wigley F, Smith CK. Controlled double-blınd

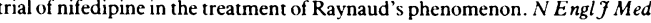
1983;308:880-3.

14 Souza J, Kraus A, Gonzalez-Amaro R, Alarcon-Segovia D. Effect of the calcium channel blocker nifedipine on Raynaud's phenomenon. A controlled double-blind trial. F Rheumatol 1984:11:362-4

15 Kahar A, Weber S, Amor B, et al. Controlled trial of nifedipine in the treatment of Raynaud's phenomenon. Rev Rhum Mal Osteoartic 1982;49: $337-43$

16 Bravard P, Moore N. Nifedipine for Raynaud's phenomenon. Lance $1983 ; \mathrm{i}: 130-1$.

17 Sarkozi J, Bookman AAM, Mahon W, et al. Nifedipine in the treatment of idiopathic Raynaud's syndrome (IRS). Arthritis Rheum 1984;27 (suppl):27. 18 Rustin MHA, Cooke ED, Bowcock SA, Kirby JDT. Nifedipine for Raynaud's phenomenon. Lancet 1983;i:130.

19 Kenny J. Calcium channel blocking agents and the heart. Br Med $\mathcal{J}$ 1985;291:1150-2

20 Lindsey G, McCullough RG, Seaman J, Hawkins R, Weil J, Steigerwald J. Nifedipine may be harmful in the treatment of Raynaud's phenomeno secondary to systemic sclerosis. Arthritis Rheum 1984;27 (suppl):18.

21 Furchgott RF, Zawadzki JV. The obligatory role of endothelial cells in the relaxation of arterial smooth muscle. Nature 1980;288:373-6.

22 Singer HA, Peach MJ. Endothelium-dependent relaxation of rabbit aorta 1 and 2. F Pharmacol Exp Ther 1983;226:790-801.

23 Aldoori M, Campbell WB, Dieppe PA. Nifedipine in the treatment of Raynaud's syndrome. Cardiovasc Res 1986;20:466-70.

24 Rademaker MT, Kirby JDT, Kovacs IB. Altered in-vitro clotting and thrombolysis after oral nifedipine in normal volunteers. Angiology (in press.)

25 Jarrett PEM, Morland M, Browse NL. Treatment of Raynaud's phenomenon by fibrinolytic enhancement. BrMed f 1978;ii:523-5.

26 Blunt RJ, George AJ, Hurlow RA, Strachan CJL, Stuart J. Hyperviscosity and thrombotic changes in idiopathic and secondary Raynaud's syndrome. $\mathrm{Br} \mathcal{F}$ Haematol 1980;45:651-8.
MRC Environmental

Epidemiology Unit,

University of

Southampton,

Southampton General

Hospital, Southampton

SO9 4XY

D J P Barker, FRCP, director

C Osmond, PHD, statistician

Department of Child

Health, University

of Bristol, Royal Hospital

for Sick Children, Bristol

BS2 8BJ

J Golding, PHD, Wellcome

senior lecturer

MRC National Survey of

Health and Development,

Department of Community

Medicine, University

College London and The

Middlesex Hospital

Medical School, London

WC1E 6EA

D Kuh, MA, scientist

M E J Wadsworth, PHD,

director

Correspondence to:

Professor Barker.

Br.Med f 1989;298:564-7

\title{
Growth in utero, blood pressure in childhood and adult life, and mortality from cardiovascular disease
}

\author{
D J P Barker, C Osmond, J Golding, D Kuh, M E J Wadsworth
}

\begin{abstract}
In national samples of 992110 year olds and 3259 adults in Britain systolic blood pressure was inversely related to birth weight. The association was independent of gestational age and may therefore be attributed to reduced fetal growth. This suggests that the intrauterine environment influences blood pressure during adult life. It is further evidence that the geographical differences in average blood pressure and mortality from cardiovascular disease in Britain partly reflect past differences in the intrauterine environment.
\end{abstract}

Within England and Wales 10 year olds living in areas with high cardiovascular mortality were shorter and had higher resting pulse rates than those living in other areas. Their mothers were also shorter and had higher diastolic blood pressures. This suggests that there are persisting geographical differences in the childhood environment that predispose to differences in cardiovascular mortality.

\section{Introduction}

Two lines of evidence suggest that an adverse environment during early childhood has an important effect on the later risk of cardiovascular disease. Firstly, height, which is determined largely by growth in early childhood,' has been shown to be inversely related to cardiovascular mortality in prospective studies in Norway, ${ }^{2}$ Finland, ${ }^{3}$ and among male civil servants in London. ${ }^{4}$ There is also a close inverse correlation between average height and cardiovascular mortality in the counties of England and Wales (Barker et al, unpublished). Secondly, there is a close relation between differences in cardiovascular mortality between one part of England and Wales and another and differences in infant mortality 60 and more years ago. ${ }^{56}$ The geographical distribution of cardiovascular disease is more closely related to neonatal and maternal death rates in the past than to postneonatal rates. ${ }^{6}$ This points to the importance of the environment during intrauterine rather than early postnatal life.

Blood pressure has been suggested as one link between the intrauterine environment and risk of cardiovascular disease. ${ }^{6}$ We have therefore examined the relations among blood pressure, pulse rate, and intrauterine influences, as measured by birth weight, gestational period, mother's height, and mother's blood pressure. To do this we have used data from two large national samples, one of children aged 10 and another of adults aged 36 .

We used geographical comparisons within England and Wales to examine the relation between intrauterine influences and cardiovascular disease. We compared geographical variations in mothers' heights and blood pressures, and in the birth weights of their children, with differences in cardiovascular mortality.

\section{Subjects and methods}

1970 Cohort-Roughly $97.5 \%$ of all births in Great Britain during one week in April 1970 were included in the British births survey. ${ }^{7.9}$ Information recorded at around the time of birth included birth weight, gestational period, and mother's blood pressure at first attendance at the antenatal clinic. Social class at birth was derived from father's occupation. Surviving children were followed up at 10 years when they were examined by clinical medical officers. Their heights, weights, blood pressures, and pulse rates were measured by standardised procedures. Mothers' heights were also recorded. Blood pressure was measured towards the end of the examination by using a sphygmomanometer. The cuff size, which was recorded, was sufficient to encircle the upper arm completely and cover two thirds of its length. Diastolic 